\title{
Long term sequelae of sex steroid treatment in the management of constitutionally tall stature
}

\author{
W J de Waal, M Torn, S M P F de Muinck Keizer-Schrama, R S R Aarsen, S L S Drop
}

\begin{abstract}
Aim-To evaluate possible long term side effects of high doses of sex steroids in the management of constitutionally tall stature, with special attention to hypothalamic-gonadal function.

Methods-Sixty four tall adult men and 180 tall adult women, who received supraphysiological doses of sex hormones during puberty, were interviewed in a standardised way at a mean follow up period of 10 years after cessation of treatment. Sixty one untreated tall adult men and 94 untreated tall adult women served as controls.
\end{abstract}

Results-The majority of the subjects were satisfied with their decision regarding hormone treatment. Seventy seven per cent of the women and $78 \%$ of the men reported one or more side effects during treatment. Most side effects were mild. In women, only $3 \%$ stopped treatment because of an adverse event; in men, the reported side effects never stopped treatment. The frequency of reported side effects in women was higher during treatment with high doses of oestrogens than during oral contraceptive use, indicating a dose dependent relationship. Amenorrhoea of longer than six months after cessation of therapy was found in $5 \%$. Menstrual cycle characteristics of previously treated women were comparable with controls. Malignancy was not reported. Information about a total of 127 pregnancies was obtained and revealed no distinct differences in details and outcome between previously treated women and men, and controls.

Conclusions-At a mean follow up of 10 years there is no evidence that pharmacological doses of sex hormones have a long term effect on reproductive function. However, this period is still too short to draw definite conclusions.

(Arch Dis Child 1995; 73: 311-315)

Keywords: constitutional tall stature, sex steroid treatment, side effects, outcome.

Division of Endocrinology W J de Waal $M$ Torn

S M P F de Muinck

Keizer-Schrama

S L S Drop Correspondence to:
Dr W J de Waal, Sophia Dr W J de Waal, Sophia Children's Hospital, Division of Endocrinology, Dr Molewaterplein 60 3015 GJ Rotterdam,
The Netherlands.

Accepted 5 June 1995

Treatment of tall adolescent boys and girls with high doses of sex steroids in order to reduce their final height is a widespread practice. ${ }^{1-10}$ In our hospital we have been treating constitutionally tall children since 1968 . In girls, oestrogens have been used (ethinyloestradiol $200 \mu \mathrm{g} /$ day, range: $100-300 \mathrm{mg} /$ day) in combination with progestagens (medroxyprogestrone $5-10 \mu \mathrm{g} /$ day, orally) every 5-10 days of the month; boys have been treated with androgens (testosterone esters in various regimens with a total monthly dose of up to $1000 \mathrm{mg}$.).

Over the years height reduction by means of supraphysiological doses of sex hormones has been much discussed, not only because of the problems in assessing the real growth reducing efficacy and the lowest effective dose, but also because of the possibility of unwanted side effects. In this respect special attention has been focused on haemostasis, ${ }^{11}$ lipid metabolism, ${ }^{12}$ and the function of the hypothalamicgonadal axis. ${ }^{13} 14$ The impressive bulk of available data on the association between long term oral contraceptive use and possible health risks (reviewed in ${ }^{15}{ }^{16}$ ) are indispensable as they form an excellent reflection of the prospective risks in oestrogen treated girls.

So far, unwanted side effects have only been reported during treatment or shortly after its discontinuation. ${ }^{1-1017-21}$ Most side effects were found to be mild and reversible. Suppression of the hypothalamic-gonadal axis induced by the pharmacological doses of sex steroids was found to be reversible. ${ }^{1314}$ However, the possibility of a long term suppressive effect of sex hormone treatment on reproductive function in boys has been postulated. $^{22}$ In a recent study in 43 previously treated tall men and 30 untreated tall controls we could not confirm this suggestion. ${ }^{23}$ In girls, the ultimate 'proof' of complete reversibility of hypothalamic-gonadal suppression - pregnancy - has been reported in various single cases. ${ }^{1-4689}$

To offer further data on acceptance and possible long term effects of high doses of sex steroids in the management of constitutionally tall stature we interviewed tall adult men and women at a mean follow up period of 10 years after discontinuation of height reductive therapy by means of a self constructed questionnaire. Our main field of interest was the functioning of the hypothalamic-gonadal axis. Since our study was intended to be noninvasive, this was covered by questions about menstruation, gynaecological complaints and childbearing. Tall adult men and women who had not received treatment during their pubertal period served as controls.

\section{Methods}

Since the introduction of height reducing treatment in our institute in 1968, 247 men and 423 women who were seen at adolescence for evaluation of their constitutionally tall stature had reached the age of 18 at the time of our follow up study. All were contacted by mail to
PATIENTS 
Table 1 Clinical data on 125 adult men and 272 adult women with constitutionally tall stature. Data expressed as mean (SD) and range

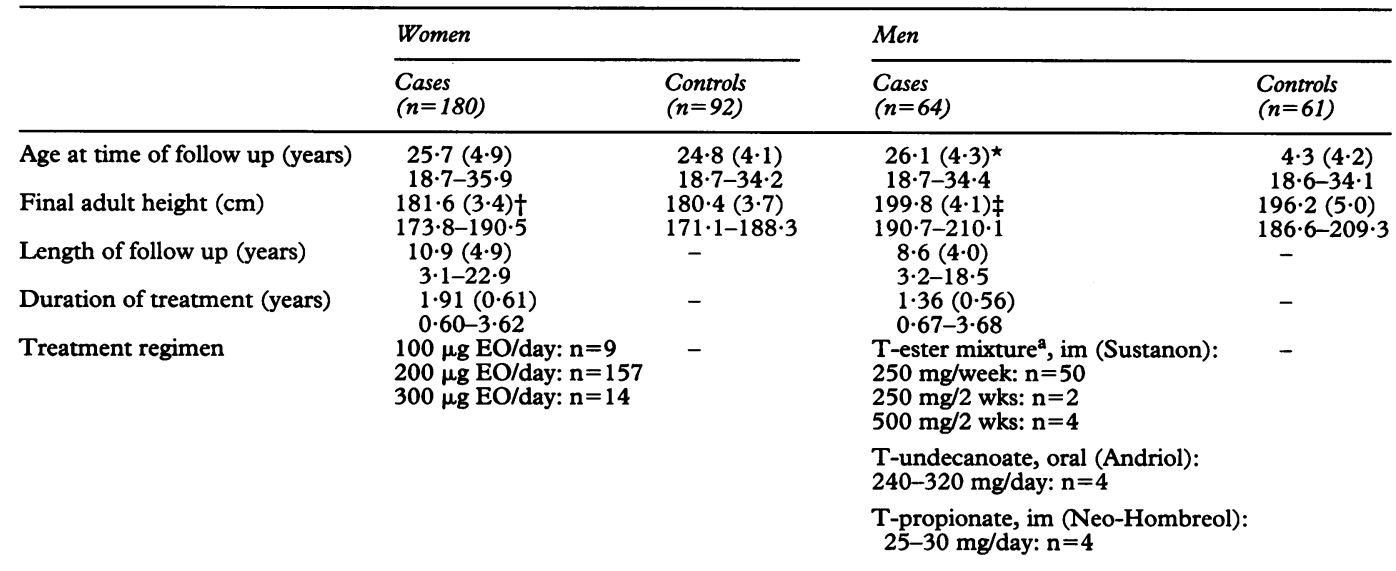

$\mathrm{EO}=$ ethinyloestradiol; im =intramuscular; $\mathrm{T}=$ testosterone.

a Mixture of $\mathrm{T}$-propionate, $\mathrm{T}$-fenylpropionate, $\mathrm{T}$-isohexanoate, and $\mathrm{T}$-decanoate.

${ }^{\star} \mathrm{p}<0.05, \mathrm{tp}<0.01, \neq \mathrm{p}<0.0001$, cases $v$ controls.

participate in the study. Second mailings were sent to those who did not respond to the first mailing. This was part of a large follow up study of constitutionally tall stature, including auxological and psychosocial assessments. Data on auxology and psychology will be reported elsewhere.

During their puberty, 102 men and 249 women had been treated for tall stature (cases). The indication for the therapy was usually a predicted final height $>2.5 \mathrm{SD}$ above the mean $(>180 \mathrm{~cm}$ for girls and $>200 \mathrm{~cm}$ for boys). Occasionally, therapy was initiated in idiopathic scoliosis. Controls were 145 men and 174 women who had chosen not to undergo treatment for various reasons such as satisfaction with the given height prognosis or uncertainty about possible side effects. Two hundred and nine men ( 95 cases and 114 controls) and 326 women (203 cases and 123 controls) responded to our mailing. Of the responders, 125 men (64 cases and 61 controls) and 272 women (180 cases and 92 controls) agreed to participate in the study. Clinical data on the participants are summarised in table 1. All participants gave informed consent.

\section{METHODS}

All participants were interviewed in a standardised way by one investigator (WdW). In women, the standardised interview included questions about satisfaction and possible side effects of hormone treatment, oral contraception, menstrual cycle characteristics (without oral conceptive use), pregnancy, and gynaecological complaints. Men were asked about satisfaction and possible side effects of hormone treatment and about their offspring. The standardised possibilities of adverse effects during sex hormone treatment were extracted from published reports. Most of the participants were interviewed in an outpatient clinic setting. Five women and one man (all cases) were interviewed by telephone.

If a subject had sought gynaecological consultation because of suspected subfertility additional information was asked for after informed consent was obtained.
The protocol was approved by the ethics committee of Academic Hospital, Erasmus University, Rotterdam.

\section{STATISTICS}

Differences between groups were tested using Wilcoxon's two sample test. In women, cases were grouped according to their total daily ethinyloestradiol dosage. Differences between these three groups were tested with the Kruskal-Wallis test. In men, no statistics were performed on the various treatment regimens because of the small numbers in the groups. $\chi^{2}$ tests (with Yates' correction when appropriate) were used in case of a contingency distribution. Incidence rates of adverse events, pregnancy outcome, and gynaecological consultation were compared using Fisher's exact test.

\section{Results \\ GIRLS \\ Treatment and adverse effects}

In the control group, four women (4\%) regretted their decision not to undergo hormone treatment for height reduction. Ninety three per cent of the case group were satisfied with the result of their treatment; 7\% showed dissatisfaction. The main reason for dissatisfaction was the small effect of the treatment compared with the given height prediction. Eleven per cent of the cases would not apply for height reduction treatment again; they were worried about the possibility of long term side effects or thought that tall stature in girls was less a problem nowadays.

Separate possible adverse effects during hormone treatment and their reported frequency are listed in table 2 . One hundred thirty nine women $(77 \%)$ said they were troubled by one or more side effects during treatment; 41 women $(21 \%)$ could not remember any adverse effect. Five women (3\%) stopped treatment because of adverse events: persistent nausea, suspected ovarian cyst, enlarged uterus, amaurosis fugax, and headache. We found no relation between the 
Table 2 Number of reported adverse effects (\%) during oestrogen treatment and oral contraceptive use in constitutionally tall women

\begin{tabular}{|c|c|c|c|}
\hline \multirow[b]{2}{*}{ Type } & \multirow{2}{*}{$\begin{array}{l}\text { Ethinyloestradiol } \\
\text { treatment in } \\
\text { cases } \\
(n=180)\end{array}$} & \multicolumn{2}{|c|}{ Oral contraceptive use } \\
\hline & & $\begin{array}{l}\text { Cases } \\
(n=160)\end{array}$ & $\begin{array}{l}\text { Controls } \\
(n=87)\end{array}$ \\
\hline Headache/migraine & $23(13)$ & $22(14)$ & $7(8)$ \\
\hline Nausea/vomiting & $25(14)$ & $4(3)$ & $5(6)$ \\
\hline Vaginal discharge & $24(13)$ & $9(6)$ & $10(11)$ \\
\hline Pigmentation of areola and nipples & $48(27)$ & - & - \\
\hline Weight gain & $74(41)$ & $34(21)$ & $26(30)$ \\
\hline Leg cramps at night & $36(20)$ & $5(3)$ & $6(7)$ \\
\hline Change in psychological or sexual behaviour & $6(3)$ & $15(9)$ & $12(14)$ \\
\hline Galactorrhoea & $8(4)$ & - & $2(2)$ \\
\hline Hypertrichosis & $6(3)$ & - & - \\
\hline Thrombosis & - & $2(1)$ & - \\
\hline Hypertension & $3(2)$ & $1(0 \cdot 6)$ & $1(1)$ \\
\hline Bleeding disturbances & $17(9)$ & $31(21)$ & $14(16)$ \\
\hline Interval bleeding & $10(6)$ & $25(16)$ & $12(14)$ \\
\hline No bleeding & $2(1)$ & $3(2)$ & $1(1)$ \\
\hline Metrorrhagia & $4(2)$ & $1(0 \cdot 6)$ & $1(1)$ \\
\hline Oligomenorrhoea & $1(0 \cdot 5)$ & - & - \\
\hline Dysmenorrhoea & - & $2(1)$ & - \\
\hline Cysts or tumours in breasts & $2(1)$ & $2(1)$ & $2(2)$ \\
\hline Cysts or tumours in uterus & $1(0 \cdot 5)$ & $2(1)$ & $1(1)$ \\
\hline Cysts or tumours in ovaries & $1(0.5)$ & $1(0 \cdot 6)$ & $2(2)$ \\
\hline Other & $27(15)$ & $8(5)$ & $3(3)$ \\
\hline Accelerated pubertal development & $10(6)$ & - & - \\
\hline Polyphagia (bulimia?) & $7(4)$ & $1(0 \cdot 6)$ & $1(1)$ \\
\hline Striae & $5(3)$ & - & - \\
\hline Dizziness & $2(1)$ & - & - \\
\hline Amaurosis fugax & $1(0 \cdot 5)$ & - & - \\
\hline Loss of taste & $1(0.5)$ & - & - \\
\hline$M$ pfeiffer & $1(0.5)$ & - & - \\
\hline Candidiasis & - & $3(2)$ & - \\
\hline Fluid retention & - & $2(1)$ & $1(1)$ \\
\hline Dry eyes & - & $1(0 \cdot 6)$ & - \\
\hline Gall stones & - & $1(0.6)$ & - \\
\hline Endometriosis & - & $1(0.6)$ & - \\
\hline Exanthema & - & - & $1(1)$ \\
\hline
\end{tabular}

total daily dosage of ethinyloestradiol and the number of reported adverse effects.

\section{Menstruation and oral contraception}

Data on recurrence of menstruation after cessation of treatment are given in table 3 . In $82 \%$ of the case group a regular menstrual cycle was reported, compared to $74 \%$ of the controls $(p=0 \cdot 15)$. The reported duration of the menstrual cycle was $31 \cdot 6(\mathrm{SD} 12 \cdot 2)$ days for cases and $32 \cdot 4(11 \cdot 3)$ days for controls $(p=0 \cdot 11)$. When we calculated the reported cycle length of the regular menstruating women only, the mean duration became shorter: $28.6(2.2)$ days and $29.3(5.3)$ for cases and controls respectively $(p=0 \cdot 42)$. This was because women with irregular menstrual cycles had a higher frequency of very long cycles. The reported duration of the menses was slightly, though significantly, different between cases and controls: $5.3(1.5)$ days and $6.1(1.7)$ days respectively $(p<0 \cdot 01)$. When we calculated the duration of the menses of the regularly menstruating women only, this difference became smaller, but was still significant at 5.3 (1.4) days and 5.9(1.4) days for cases and controls respectively, $p<0.01$. No difference was found in the proportion of intermenstrual bleeding between regularly menstruating cases and controls.

Table 3 Reported recurrence of menstruation after cessation of treatment in 180 treated constitutionally tall women

\begin{tabular}{lr}
\hline Recurrence & No \\
\hline After 1 month & 114 \\
After 1-6 months & 51 \\
After 6 months-1 year & 5 \\
More than 1 year & 4 \\
Unknown (went onto oral contraceptives) & 3 \\
Cannot remember & 3
\end{tabular}

The use of oral contraceptives and the proportion of reported side effects was not significantly different between case group and the controls. The separate possible adverse effects during oral contraceptive use and their reported frequency in cases and controls are listed in table 2 . There was no significant difference in the distribution of each of the separate reported adverse effects between the groups ( $\mathrm{p}$ values $>0 \cdot 05$ ).

\section{Pregnancy}

Details and outcome of 100 pregnancies are listed in table 4. There was no significant difference between case group and the controls in the distribution of the number of miscarriages, the time to achievement of pregnancy, and the number of pregnancies after fertility induction.

For various reasons 57 cases and 20 controls had consulted a gynaecologist at some time. There was no significant difference in these proportions $(p=0 \cdot 11)$. Subfertility, gynaecological infections, and menstrual cycle disturbances were most often reported as the reason for consultation. Eleven cases and one control consulted a gynaecologist for infertility. This difference appeared to be statistically nonsignificant between the groups $(p=0.07)$. The various causes for subfertility in these women were endometriosis, uterine or tubal abnormalities, hyperprolactinaemia, uterine myoma, and ovalutory dysfunction. Of the 12 women, five (four cases and one control) succeeded in becoming pregnant through fertility induction (table 4). In addition, two cases became pregnant spontaneously. The remaining four cases were still under gynaecological supervision at the time of the interview. In the case group, women who consulted a gynaecologist had not

Table 4 Details and outcome of pregnancies in constitutionally tall men and women

\begin{tabular}{|c|c|c|}
\hline & Cases & Controls \\
\hline Women & $(n=40)$ & $(n=16)$ \\
\hline No of pregnancies & 63 & \\
\hline \multicolumn{3}{|l|}{ Outcome } \\
\hline Induced abortion & 4 & 1 \\
\hline Miscarriage & 8 & 1 \\
\hline Extrauterine pregnancy & 3 & - \\
\hline Hydatidiform mole & - & 1 \\
\hline Pregnant at time of study & 4 & 1 \\
\hline Normal birth & 43 & 23 \\
\hline 1 Child & 22 & 7 \\
\hline 2 Children & 10 (1 twin) & 5 \\
\hline 3 Children & & 2 \\
\hline \multicolumn{3}{|l|}{ Details } \\
\hline Toxaemia & 4 & - \\
\hline Symphysiolysis & - & 1 \\
\hline Prenatal blood loss & 1 & - \\
\hline Manual removal of placenta & - & 1 \\
\hline Postpartum haemorrhage & 1 & - \\
\hline Premature contractions & 1 & - \\
\hline Fertility induction & 4 & 1 \\
\hline \multicolumn{3}{|c|}{ Time before achievement of pregnancy } \\
\hline Less than 1 year & 51 & 25 \\
\hline Between 1 and 2 years & 2 & 1 \\
\hline More than 2 years & 8 & 1 \\
\hline Men & $(n=6)$ & $(n=10)$ \\
\hline No of pregnancies in partners & 11 & \\
\hline \multicolumn{3}{|l|}{ Outcome } \\
\hline Miscarriage & 1 & 1 \\
\hline Normal birth & 10 & 15 \\
\hline \multirow{2}{*}{\multicolumn{3}{|c|}{ Details }} \\
\hline & & \\
\hline Intrapartum asphyxia & - & 2 \\
\hline \multicolumn{3}{|c|}{ Time before achievement of pregnancy } \\
\hline Less than 1 year & 10 & 15 \\
\hline Between 1 and 2 years & 1 & - \\
\hline More than 2 years & - & 1 \\
\hline
\end{tabular}


received a significantly different total daily dose of ethinyloestradiol during adolescence than women who had not consulted a gynaecologist $(p=0 \cdot 11)$. In addition, the total daily dosage of ethinyloestradiol in women who sought gynaecological consultation because of subfertility did not differ from that of women who consulted a gynaecologist for other reasons.

\section{BOYS}

Treatment and adverse effects

In the control group, six men (10\%) regretted their decision not to have undergone androgen treatment for height reduction. They were significantly taller than those who showed no regret at their choice: mean final height 202.8 (SD 5.4) $v 195 \cdot 5(4 \cdot 4) \mathrm{cm}, \mathrm{p}=0.004$.

Eighty six per cent of the case group were satisfied with the result of their treatment; $14 \%$ showed dissatisfaction. The main reason for dissatisfaction was the small effect of the treatment compared with the given height prediction. Eight per cent would not apply for height reducing treatment again, because of side effects or uncertainty about long term effects.

Fifty men (78\%) said they had been troubled by one or more side effects during treatment. Fourteen men $(22 \%)$ could not remember any adverse effects. Aggravation of acne was the most commonly reported effect (39\%), followed by painful injections $(16 \%)$, weight gain $(14 \%)$, gynaecomastia $(13 \%)$, muscle aches $(13 \%)$, oedema $(9 \%)$, and change in psychological or sexual behaviour $(5 \%)$.

\section{Pregnancy in partners}

Details and outcome of 27 pregnancies in partners of cases and controls are listed in table 4 . None of the men who were childless at the time of the interview wished to have children at that time. There was no significant difference between the cases and controls regarding outcome of pregnancy in their partners and the length of time before achievement of pregnancy.

\section{Discussion}

Long term follow up data on sex steroid treatment of constitutionally tall adolescents are lacking. In order to obtain an insight in possible long term side effects we performed a non-invasive controlled study and focused on the function of the hypothalamic-gonadal axis. In spite of the non-invasive character of our study, cases were more willing to participate in this follow up than controls. It is possible that this may have biased the results. Cases would perhaps have been more likely to have linked particular conditions with their past hormone treatment, and this may have led to overreporting. The results must therefore be interpreted with caution.

Our study showed that many patients experienced one or more side effects during treatment. Fortunately most of them were mild and led to cessation of treatment in only $3 \%$ of the women. In men, treatment was not discontinued because of adverse effects. Our findings are in general in agreement with the side effects reported by others. ${ }^{1-10} 17-21$

In girls, adverse effects of oestrogens occurred more often during treatment than during oral contraceptive use. This reflects a dose dependent effect of oestrogens on the incidence of adverse events. The scale of reported side effects reported during oral contraceptive use was not significantly different between cases and controls and was of the same order as previously described. ${ }^{24} 25$ Two cases reported thrombosis during oral contraceptive use. Despite the fact that the risk of thromboembolism increases with the oestrogen dose, ${ }^{26}$ we did not find any cases of thrombosis during treatment. One girl who had a history of amaurosis fugax might have had thromboembolism. However, no haemostatic changes were found at that time. In general, thrombosis is found to be an uncommon side effect of height reducing treatment ${ }^{11718}$; whenever thrombosis occurred it mostly coincided with other risk factors for thromboembolism such as immobilisation. Amenorrhoea of longer than six months after cessation of height reducting treatment treatment was reported in about $5 \%$ of cases. The incidence of amenorrhoea following cessation of oral contraception is about $0.5 \% .^{27}$ In addition, the overall prevalence of secondary amenorrhoea of more than six months in women aged $15-34$ years is about $1 \cdot 3 \% .^{28}$ This may suggest an increase in amenorrhoea after height reducing treatment. It should be noted, however, that there are no convincing data showing that oral contraceptive use is causally related to amenorrhoea and that other risk factors for amenorrhoea, such as smoking, nutrition, and exercise, were not adequately adressed. ${ }^{27} 29$ We found no important differences in menstrual cycle characteristics between cases and controls. This implies that no important hormonal imbalance is present in previously treated tall women. Malignancy was not reported in our study. The possibility of a dose dependent effect and a relation between either oral contraceptive use at a young age or duration of oral contraceptive use and increased risks of breast cancer ${ }^{30}$ raises the need for long term follow up in patients treated with pharmacological doses of oestrogens. In our study, only 49 of the 180 cases were older than 30 years at time of the follow up. Therefore, our mean follow up period of almost 11 years in women is still too short to give any answer to this important issue.

In boys, aggravation of acne was by far the most commonly reported side effect. This is in agreement with others. ${ }^{35}$ A causal relationship with androgen treatment is likely, as shown by Fyrand et al. ${ }^{31}$ Gynaecomastia occurred in $13 \%$ of the cases, probably because of the increased peripheral conversion of androgens to oestrogens. Since gynaecomastia is rather prevalent in population studies in boys, ${ }^{32}$ it is hard to say whether this condition is increased. In one patient, surgical correction was necessary several years after cessation of treatment .

Thus far, only casuistic data have been available on successful pregnancies after height 
reducing treatment. ${ }^{1-4689}$ In our follow up study information about a total of 127 pregnancies was obtained and revealed no distinct differences in details and outcome of pregnancies between treated women and men and controls. These results imply that long term effects of high doses of sex hormones on fertility are unlikely. It is tempting to draw definite conclusions at this time, but one should not forget the social trend to have children at a later age and the fact that the control group in men was significantly younger. In addition, the finding in women that a higher proportion of cases (though not significantly so) had sought gynaecological consultation because of subfertility should not be ignored. However, this latter finding is hard to interpret. There is always the possibility of bias by overreporting in cases, as discussed above. Furthermore, additional information about the causes for subfertility in these women showed no clear systematical pattern, indicating that a certain pathophysiological mechanism is unlikely. Finally, the prevalence of infertility in the normal population is of the same order of magnitude (10-25\%, depending on the definition used ${ }^{33}$ ). Besides, the meaning of significantly higher plasma concentrations of follicle stimulating hormone in previously treated tall adult men in the presence of normal sperm quality, normal plasma testosterone, and normal testis volume remains to be established. ${ }^{23}$ Therefore, definite conclusions on the influence of pharmacological doses of sex hormones on fertility cannot be drawn yet. But for now, our data are reassuring, since there is no clear evidence that treatment with high doses of sex steroids causes any harmful effects on reproductive function in men or women.

In summary, treatment of tall adolescent boys and girls with high doses of sex hormones to reduce their final height was approved by most of the patients, despite the fact that many of them experienced side effects during the treatment. Most side effects were mild. The incidence of side effects is probably dose dependent. Post-treatment amenorrhoea of longer than six months was found in $5 \%$ of the women. No important differences in menstrual cycle characteristics were found between cases and controls. Information on a total of 127 pregnancies was obtained and revealed no distinct differences in details and outcome between treated men and women and controls. At a mean follow up period of 10 years, there is no evidence that pharmacological doses of sex hormones have a long term effect on reproductive function or cancer risks. However, this period is still too short to draw definite conclusions.

We kindly thank the Foundation for Children's Stamps, Leiden, The Netherlands for their generous gift to support this study. Dr B C J M Fauser, gynaecologist, is greatly appreciated for his critical comments. We thank Frank Bekkering, Evelin help in selecting the data.

1 Wettenhall NH, Cahill C, Roche AF. Tall girls: a survey of 15 years of management and treatment. F Pediatr 1975; 86: $602-10$.

2 Prader A, Zachmann M. Treatment of excessively tall girls and boys with sex hormones. Pediatrics 1978; 62: 1202-10.
3 Crawford JD. Treatment of tall girls with estrogen. Pediatrics 1978; 62: 1189-95.

4 Andersen $\mathrm{H}$, Jacobsen BB, Kastrup KW, et al. Treatment of girls with excessive height prediction. Acta Paediatr Scand 1980; 69: 293-7.

5 Brämswig JH, Schellong G, Borger HJ, Breu $H$. Testosteron-Therapie hochwüchsiger Jungen. Dtsch Med Wochenschr 1981; 106: 1656-61.

6 Stöver B, Kollmann F. Ergebnisse der Behandlung hochüchsiger Mädchen mit conjugierten Ostrogenen. hochüchsiger Mädchen mit conjugierten

7 Brämswig JH, Lengerke v HJ, Schmidt H, Schellong G. The results of short-term ( 6 months) high-dose testosterone treatment on bone age and adult height in boys of excessively tall stature. Eur $\mathcal{F}$ Pediatr 1988; 148: 104-6.

8 Grüters A, Heidemann $\mathrm{P}$, Schlüter $\mathrm{H}$, Stubbe $\mathrm{P}$, Weber B, Helge $H$. Effect of different oestrogen doses on final height reduction in girls with constitutional tall stature. Eur $f$ Pediatr 1989; 149: 11-13.

9 Normann EK, Trygstad O, Larsen S, Dahl-Jorgensen K. Height reduction in 539 tall girls treated with three different dosages of ethinyloestradiol. Arch Dis Child 1991; 66: 1275-8.

10 Joss EE, Zeuner J, Zurbrügg RP, Mullis PE. Impact of different doses of ethinyl oestradiol on reduction of final height in constitutionally tall girls. Eur $\mathcal{J}$ Pediatr 1994; 153: 797-801.

11 Muntean W, Borkenstein M. Hemostatic changes in tall girls treated with high doses of ethinylestradiol. Eur $\mathcal{f}$ Pediatr 1980; 134: 245-8.

12 Hinkel GK, Hanefeld $M$, Jaross W, Leonhardt W, Trübsbach A. Effect of high doses of oestrogens and androgens on lipoproteins: observations in the treatment of excessive growth with sexual hormones. Exp Clin Endocrinol 1985; 86: 17-25.

13 Hanker JP, Schellong G, Schneider HPG. The functional state of the hypothalamo-pituitary axis after high dose oestrogen therapy in excessively tall girls. Acta Endocrinol 1979; 91: 19-29.

14 Brämswig JH, Nieschlag E, Schellong G. Pituitary-gonadal function in boys after high dose testosterone treatment for excessively tall stature. Acta Endocrionol 1984; 107:

5 Grimes DA. The safety of oral contraceptives: epidemiologic insights from the first 30 years. Am $\mathcal{f}$ Obstet Gynecol logic insights from
1992; 166: 1950-4.

16 Kaunitz AM. Oral contraceptives and gynecologic cancer: an update for the 1990s. Am $\mathcal{F}$ Obstet Gynecol 1992; 167: $1171-6$.

17 Trygstad $O$. Oestrogen treatment of adolescent tall girls; short term side effects. Acta Endocrinol 1986279 (suppl): $170-3$

18 Werder EA, Waibel P, Sege D, Flury R. Severe thrombosis during oestrogen treatment for tall stature. Eur $\mathcal{f}$ Pediatr 1990; 149: 389-90.

19 Panteon E, Loumaye E, Maes M, Malvaux P. Occurrence of prolactinoma after estrogen treatment in a girl with constitutionally tall stature. F Pediatr 1988; 113 : 337-9.

20 Traupe $\mathrm{H}$, Mühlendahl von KE, Brämswig JH, Happle R. Acne of the fulminans type following testosterone therapy in three excessively tall boys. Arch Dermatol 1988; 124: in thre

21 Commentz JC, Conrad C, Stahnke N, Willig RP. Priapism during testosterone treatment for reducing final height in during testosterone treatment for red

22 Willig RP, Bettendorf M, Hinkel GK, Schwarz HP, Schulze W. Androgen treatment of tall stature during puberty may reduce sperm quality in adult life. Horm Res 1992; 37 (suppl 4): 3 .

23 Waal de WJ, Vreeburg JTM, Bekkering F, et al. High dose testosterone therapy for reduction of final height in constitutionally tall boys: does it influence testicular function in adulthood? Clin Endocrinol 1995; 43: 87-95.

24 Hillard PJA. The patient's reaction to side effects of oral contraceptives. Am 7 Obstet Gynaecol 1989; 161: 1412-5.

25 Akerlund $M$, Rode A. Comparative profiles of reliability, cycle control and side effects of two oral contraceptive cycle control and side effects of two oral contraceptive mg or $20 \mathrm{mg}$ ethinyl oestradiol. Br f Obstet Gynaecol 1993; 100: $832-8$.

26 Iman WHW, Vessey MP, Westerholm B, et al. Thromboembolic disease and the steroidal content of oral contraceptives: a report to the committee on safety of contraceptives: a report to
drugs. $B M \mathcal{F} 1970$; ii: $203-9$.

27 Hull MGR, Bromham DR, Savage PE, Barlow TM Hughes AO, Jacobs HS. Post-pill amenorrhea: a causal study. Fertil Steril 1981; 36: 472-6.

28 Münster K, Schmidt L, Helm P. Secondary amenorrhoea: prevalence and medical contact - a cross-sectional study from a Danish county. Br $\mathcal{F}$ Obstet Gynaecol 1992; 99: 430-3.

29 Gold EB, Bush T, Chee E. Risk factors for secondary amenorrhea and galactorrhea. Int $\mathcal{f}$ Fertil 1994; 39: 177-84.

30 Rushton L, Jones DR. Oral contraceptive use and breast cancer risk: a meta-analyses of variations with age at diagnosis, parity and total duration of oral contraceptive use. Br f Obstet Gynaecol 1992; 99: 239-46.

31 Fyrand $\mathrm{O}$, Fiskaadal HJ, Trygstad O. Acne in pubertal boys und 1992; 72: 148-9.

32 Braunstein GD. Gynecomastia. N Engl f Med 1993; 328: 490-5.

33 Greenhall $\mathbf{E}$, Vessey $M$. The prevalence of subfertility: a review of the current confusion and a report of two new studies. Fertil Steril 1990; 54: 978-83. 